\begin{tabular}{|c|c|c|c|}
\hline \multirow[t]{2}{*}{ Variable name } & \multicolumn{2}{|c|}{ Node status } & \multirow[t]{2}{*}{ p-value } \\
\hline & Positive nodes & Negative nodes & \\
\hline \multicolumn{4}{|l|}{ Characteristics of the women } \\
\hline Age & $44.75(8.95)$ & $45.33(10.34)$ & 0.731 \\
\hline BMI & $24.92(4.85)$ & $24.71(4.35)$ & 0.816 \\
\hline Performance status & & & 0.037 \\
\hline ECOG 0 & $28(87.5)$ & $355(90.8)$ & \\
\hline ECOG 1 & $3(9.4)$ & $10(2.6)$ & \\
\hline Not reported & $1(3.1)$ & $26(6.6)$ & \\
\hline Smoker & & & 0.266 \\
\hline Yes & $24(75.0)$ & $228(58.3)$ & \\
\hline No & $4(12.5)$ & $70(17.9)$ & \\
\hline Not reported & $4(12.5)$ & $93(23.8)$ & \\
\hline \multicolumn{4}{|l|}{ Characteristics of the tumor } \\
\hline Volume of the tumor & $3427.28(6904.14)$ & $1747.19(5681.87)$ & 0.189 \\
\hline Clinical size of the tumor & & & 0.343 \\
\hline$<30 \mathrm{~mm}$ & $22(68.8)$ & $306(78.3)$ & \\
\hline$\geq 30 \mathrm{~mm}$ & $8(25.0)$ & $74(18.9)$ & \\
\hline Not reported & $2(6.2)$ & $11(2.8)$ & \\
\hline Diameter of the tumor & & & 0.006 \\
\hline$\leq 20 \mathrm{~mm}$ & $21(65.6)$ & $329(84.1)$ & \\
\hline$>20 \mathrm{~mm}$ & $11(34.4)$ & $60(15.3)$ & \\
\hline Not reported & $0(0.0)$ & $2(0.5)$ & \\
\hline Histology of the tumor & & & 0.555 \\
\hline Squamous carcinoma & $1(3.1)$ & $18(4.6)$ & \\
\hline Adenocarcinoma & $23(71.9)$ & $244(62.4)$ & \\
\hline Adenosquamous carcinoma & $5(15.6)$ & $101(25.8)$ & \\
\hline \multicolumn{4}{|l|}{ Related to the conization proceedure } \\
\hline Tumor volume & $1489.49(2188.48)$ & $1378.20(3898.83)$ & 0.799 \\
\hline Dimension of tumor in cone & $15.68(6.82)$ & $14.49(6.87)$ & 0.347 \\
\hline MRI done before cone & & & 0.990 \\
\hline Yes & $23(71.9)$ & $288(73.7)$ & \\
\hline No & $5(15.6)$ & $63(16.1)$ & \\
\hline Not reported & $4(12.5)$ & $40(10.2)$ & \\
\hline Type of cone technique & & & 0.345 \\
\hline Cold knife & $3(9.4)$ & $73(18.7)$ & \\
\hline Laser & $1(3.1)$ & $21(5.4)$ & \\
\hline LEEP or LLETZ & $25(78.1)$ & $268(68.5)$ & \\
\hline Margins in the cone & & & 0.033 \\
\hline Not affected & $2(6.2)$ & $87(22.3)$ & \\
\hline Uncertain & $0(0.0)$ & $14(3.6)$ & \\
\hline Afected & $28(87.5)$ & $253(64.7)$ & \\
\hline Linfovascular invasion in the cone & & & 0.681 \\
\hline Yes & $8(25.0)$ & $90(23.0)$ & \\
\hline No & $5(15.6)$ & $44(11.3)$ & \\
\hline Not reported & $19(59.4)$ & $257(65.7)$ & \\
\hline Tumor grade of differentiation in cone & & & 0.963 \\
\hline Grade I & $7(21.9)$ & $74(18.9)$ & \\
\hline Grade II & $13(40.6)$ & $130(33.2)$ & \\
\hline Grade III & $7(21.9)$ & $80(20.5)$ & \\
\hline Tumor histology in the cone & & & 0.010 \\
\hline Squamous carcinoma & $25(78.1)$ & $256(65.5)$ & \\
\hline Adenocarcinoma & $5(15.6)$ & $109(27.9)$ & \\
\hline Adenosquamous carcinoma & $2(6.2)$ & $3(0.8)$ & \\
\hline Depth of invasion the cone & & & 0.002 \\
\hline Superficially invades stroma & $1(3.1)$ & $81(20.7)$ & \\
\hline Invades $1 / 3$ of stroma & $2(6.2)$ & $51(13.0)$ & \\
\hline Invades $2 / 3$ of stroma & $13(40.6)$ & $76(19.4)$ & \\
\hline Endocervical curettage carried out & & & 0.471 \\
\hline Yes & $24(75.0)$ & $249(63.7)$ & \\
\hline No & $7(21.9)$ & $100(25.6)$ & \\
\hline
\end{tabular}

\begin{tabular}{llll}
$\begin{array}{lll}\text { Not reported } \\
\text { Positive endocervical curretage }\end{array}$ & $1(3.1)$ & $42(10.7)$ & 0.499 \\
Yes & $3(9.4)$ & $56(14.3)$ & \\
No & $4(12.5)$ & $44(11.3)$ & \\
$\quad$ Not reported & $25(78.1)$ & $291(74.4)$ & \\
Disease free survival & $51.69(21.64)$ & $51.52(19.47)$ & 0.967 \\
Overall survival & $51.88(21.37)$ & $52.79(18.45)$ & 0.815 \\
\hline
\end{tabular}

Result(s)* In the univariate analyses we found that large tumours $(>2 \mathrm{~cm})$ and squamous or adenosquamous histopathology were associated with higher odds of positive nodes. Regarding characteristics of the cone biopsy, we observed that deep stroma invasion (2/3 of stroma) and positive margins were also associated with higher odds of positive nodes. In the multivariable adjusted model, we observed collinearity between the characteristics of the cone biopsy and therefore they were analysed separately. When accounting for tumour size and histopathology, deep invasion of the stroma was associated with 12-fold higher odds of positive nodes, but affected or uncertain margins was not.

Conclusion* In patients after cone biopsy, the association of tumors $>2 \mathrm{~cm}$ plus deep stromal invasion $(>2 / 3)$ is correlated with the higher risk of positive lymph node in early cervical cancer.

\title{
741 SAFETY PROFILE OF KEYTRUDA (PEMBROLIZUMAB) FOR THE TREATMENT OF PATIENTS WITH ADVANCED PD-L1 POSITIVE CERVICAL CANCER
}

${ }^{1} \mathrm{~F}$ Ahmed, ${ }^{1}$ I Khan, ${ }^{2} \mathrm{Z}$ Shah*, ${ }^{1} \mathrm{R}$ Garimella, ${ }^{1} \mathrm{~S}$ Mishra, ${ }^{1} \mathrm{~A}$ Bhatnagar, ${ }^{3} \mathrm{~K}$ Andrews, ${ }^{4} \mathrm{~S}$ Zaidi, ${ }^{5} \mathrm{U}$ Salman, ${ }^{6} \mathrm{SH}$ Bobba, ${ }^{7} \mathrm{~S}$ Gudapati, ${ }^{2} \mathrm{Z}$ Yukselen, ${ }^{1} \mathrm{P}$ Guntipalli, ${ }^{8} \mathrm{~J}$ Michel, ${ }^{9} \mathrm{~S}$ Ahmad, ${ }^{10} \mathrm{R}$ Zarrar, ${ }^{11} \mathrm{G}$ Enebong Nya. 'Larkin Community Hospital, Division of Clinical and Translational Research, South Miami, USA; ${ }^{2}$ Weiss Memorial Hospital, Department of Internal Medicine, USA; ${ }^{3}$ Prince Mohammad Bin Fahad University, Department of CORE, Al Khobar, Saudi Arabia; ${ }^{4}$ Lahore Medical and Dental College, College of Medicine, Pakistan; ${ }^{5}$ Bakhtawar Amin Medical and Dental College, College of Medicine, Multan, Pakistan; ${ }^{6}$ Washington University of Health and Science, College of Medicine, USA; 'Washington University of Health and Science, College of Medicine, Belize; ${ }^{8}$ Larkin Community Hospital, Department of Gynecologic Oncology, USA; ${ }^{9}$ Advent Health Cancer Institute, Department of Gynecologic Oncology, USA; ${ }^{10}$ Mayo Clinic, Department of Oncology, Rochester, USA; ${ }^{11}$ John Hopkins Hospital, Department of Gynecologic Oncology, USA

\subsection{6/ijgc-2021-ESG0.63}

Introduction/Background* Cervical cancer is the fourth most common cause of cancer-related deaths in women worldwide. With screening for precancerous lesions and vaccination for preventive human papillomavirus (HPV), a survival improvement has been observed in these patients in developed countries. In recent years, U.S. Food and Drug Administration (FDA) approved pembrolizumab for the treatment of patients with advanced cervical cancer with disease progression on or after chemotherapy whose tumors express PD-L1. Herein, we present the first systematic review discussing the safety profile of this drug.

Methodology A systematic literature search was performed on March 2021 according to PRISMA statement using PubMed, Embase, Scopus, CINAHL, Cochrane, Google Scholar, and Clinicaltrials.gov databases without any filters. The medical search terms (MeSH) utilized to conduct the search are, ' uterine cervical neoplasms' AND 'Pembrolizumab'. After a detailed primary and secondary screening done by two members of 188 studies, only 4 studies were found that discussed the safety profile of pembrolizumab. 
Result(s)* A total of 337 patients, mean age 48 years (21-76) with advanced cervical cancer who had received a median range of 1-7 previous lines of therapies, were included. In all studies, pembrolizumab was used as a single agent with a regimen of $200 \mathrm{mg}$ IV every 3 weeks. Cumulative treatment related adverse effect (AE) was reported in 60\% ( $n=201 / 337)$. Most common grade 1-2 AEs were hypothyroidism 9.2\% $(n=29 / 313)$, diarrhea $8 \%(n=22 / 337)$, fatigue $6.59 \% \quad(n=22 /$ $337)$ and rash $7 \%(n=10 / 141)$. Treatment related grade $\geq 3$ adverse reaction was reported in $8.6 \%$. Most common grade 3-4 AEs presented were transaminitis, neutropenia, rash, colitis, Guillain-Barré syndrome (GBS), and proteinuria. Also, $3.5 \%$ of patient population $(n=5 / 141)$ discontinued therapy due to treatment-related adverse events. Immune-mediated AEs were seen in $27 \%(n=31 / 118)$. The most common immunemediated AEs were hypothyroidism, hyperthyroidism, rash, colitis and GBS.

Conclusion* While early-stage cervical cancer can be curable with surgery, prognosis of patients who recur remains poor, with limited treatment options. New effective treatments are therefore much needed in this setting. Pembrolizumab (Keytruda) monotherapy demonstrated manageable safety profile in patients with advanced cervical cancer. However, more randomized clinical trials are required to establish strong conclusions.

\section{SENTINEL LYMPH NODE BIOPSY IN EARLY CERVICAL CANCER INCREASE THE LIKELIHOODS OF DISCOVERING POSITIVE LYMPH NODES COMPARED WITH PELVIC LYMPHADENECTOMY}

A Berasaluce, N Martín-Calvo, E Chacon, F Boria, N Manzour, D Vazquez, T Castellano, JÁ Mínguez, JL Alcazar, LM Chiva*. University of Navarra

\subsection{6/ijgc-2021-ESG0.64}

Introduction/Background* To assess the odds of having positive nodes in women who underwent a sentinel lymph node biopsy compared with those who underwent a lymphadenectomy in the SUCCOR study.

Methodology We used data from the SUCCOR study, a European multicentre study that collected retrospective information of 1272 women who underwent a radical hysterectomy by open or minimally invasive surgery for stage IB1 cervical cancer (FIGO 2009) between January 2013 and December 2014. After exclusions, the final sample included 1157 patients. Missing values were imputed with the median in quantitative variable and grouped in a new category in qualitative ones. The variables associated with the realisation of sentinel node biopsy were used to create a propensity score. When comparing both groups (sentinel vs non sentinel node) significant differences were found in the surgical experience, tumor size and

\section{Abstract 746 Table 1}

\begin{tabular}{|c|c|c|c|c|c|c|}
\hline \multirow[b]{3}{*}{ Variable name } & \multicolumn{3}{|l|}{ Before IPW } & \multicolumn{3}{|l|}{ After IPW } \\
\hline & \multicolumn{2}{|c|}{ Was centinel node biopsy performed? } & \multirow[t]{2}{*}{$\mathrm{p}$-value } & \multicolumn{2}{|c|}{ Was centinel node biopsy performed? } & \multirow[t]{2}{*}{ p-value } \\
\hline & Yes & No & & Yes & No & \\
\hline \multicolumn{7}{|l|}{ Characteristics of the women } \\
\hline Age & $46.57(10.56)$ & $47.25(10.98)$ & 0.395 & $45.86(10.07)$ & $46.91(11.05)$ & 0.348 \\
\hline BMI & $24.93(4.57)$ & $25.43(4.27)$ & 0.139 & $24.89(4.09)$ & $25.39(4.28)$ & 0.265 \\
\hline Performance status & & & 0.852 & & & 0.689 \\
\hline ECOG 0 & $205(91.5)$ & $774(90.1)$ & & $205(90.6)$ & $774(90.5)$ & \\
\hline ECOG 1 & $14(6.2)$ & $56(6.5)$ & & $14(7.0)$ & $56(6.1)$ & \\
\hline Not reported & $5(2.2)$ & $29(3.4)$ & & $5(2.4)$ & $29(3.4)$ & \\
\hline Smoker & & & 0.886 & & & 0.003 \\
\hline Yes & $147(65.6)$ & $476(55.4)$ & & $147(60.5)$ & $476(55.5)$ & \\
\hline No & $49(21.9)$ & $163(19.0)$ & & $49(22.0)$ & $163(19.2)$ & \\
\hline Not reported & $28(12.5)$ & $220(25.6)$ & & $28(17.5)$ & $220(25.3)$ & \\
\hline \multicolumn{7}{|l|}{ Characteristics of the tumor } \\
\hline \multirow[t]{2}{*}{ Volume of the tumor } & 7416.52 & 8029.76 & 0.417 & 9015.10 & 7714.04 & 0.445 \\
\hline & (9594.55) & (11650.87) & & (11055.48) & (11305.59) & \\
\hline Maximum diameter & & & 0.163 & & & 0.689 \\
\hline$\leq 20 \mathrm{~mm}$ & $136(60.7)$ & $477(55.5)$ & & $136(56.5)$ & 477 (56.3) & \\
\hline$>20 \mathrm{~mm}$ & $88(39.3)$ & $382(44.5)$ & & $88(43.5)$ & $382(43.7)$ & \\
\hline Linfovascular space invasion & & & 0.682 & & & 0.064 \\
\hline Yes & $125(55.8)$ & $464(54.0)$ & & $125(50.5)$ & $464(55.0)$ & \\
\hline No & $82(36.6)$ & $285(33.2)$ & & $82(41.8)$ & $285(32.7)$ & \\
\hline Not reported & $17(7.6)$ & $110(12.8)$ & & $17(7.7)$ & $110(12.3)$ & \\
\hline Parametrial space invasion & & & 0.071 & & & 0.284 \\
\hline Yes & $221(98.7)$ & $823(95.8)$ & & $221(97.3)$ & $823(96.4)$ & \\
\hline No & $2(0.9)$ & $26(3.0)$ & & $2(2.2)$ & $26(2.6)$ & \\
\hline Not reported & $1(0.4)$ & $10(1.2)$ & & $1(0.6)$ & $10(1.0)$ & \\
\hline Vaginal invasion & & & 0.770 & & & 0.543 \\
\hline Yes & $216(96.4)$ & $821(95.6)$ & & $216(94.1)$ & $821(95.8)$ & \\
\hline No & $5(2.2)$ & $22(2.6)$ & & $5(3.3)$ & $22(2.5)$ & \\
\hline Not reported & $3(1.3)$ & $16(1.9)$ & & $3(2.6)$ & $16(1.7)$ & \\
\hline
\end{tabular}

